\title{
Design of Intelligent Telemedicine Monitoring Data Transmission Network
}

\author{
Wen Dong ${ }^{1, a}$, Chongxin Liu $^{2, b}$ \\ ${ }^{1}$ Hangzhou Normal University, Hangzhou, China \\ ${ }^{2}$ Hangzhou Normal University, Hangzhou, China \\ Adongwen69@163.com, bIcx860821@163.com
}

Keywords: Telemedicine, Data Transmission, Network, Design

\begin{abstract}
The paper propose a design of the local data transmission between human body physiological parameters acquisition terminal and local intelligent monitoring terminal based on the wireless transmission technique of Zigbee and Bluetooth. In order to realize the remote transmission between Local medical monitoring terminal and remote intelligent monitoring terminal, the paper give network solutions for distal doctors to provide remote treatment. The program of monitoring terminal introduces the data processing mechanism Handler and class AsyncTask to ensure the reliability and accuracy of the data, and this can also reduce the complexity of algorithm.
\end{abstract}

\section{Introduction}

Detection device of traditional medical monitoring network does not conform to the modern medical-treatment needs [1] because of it's large volume, high power consumption, high price and inconvenience. With the accelerating social development, people's medical-treatment requirements is improved continuously. Constructing medical monitoring network based on the technique of Internet of Things and other high-tech technology [2] is one of the project of realizing intelligent medical-treatment.

The technology of the Internet of Things(IOT) has attracted highly attention of academia, industry, and news media. There are still many open issues in the definition, internal principles, architectures and system models of IOT [3]. Telemedicine is a integrated products which combine with computer, communication network technology and modern medical technology. It's a new medical service sharing system which based on the IOT [4], and its purpose is realizing the collection for the informationization of the full medical progress, the supervision of the medical supplies and the management of blood transfusion, and the digitization of hospital information, which is a brand-new health service model [5].

\section{The overall design of the system}

The network system is divided into four modules: physiological sensor acquisition module, a wireless transmission module, a local medical-treatment gateway module (client) and remote medical control terminal module (server). user can select wireless communication mode flexibly according to the distance between himself to the medical Gateway Without restrictions of time and space, the specific design diagram as shown in Figure 1. 


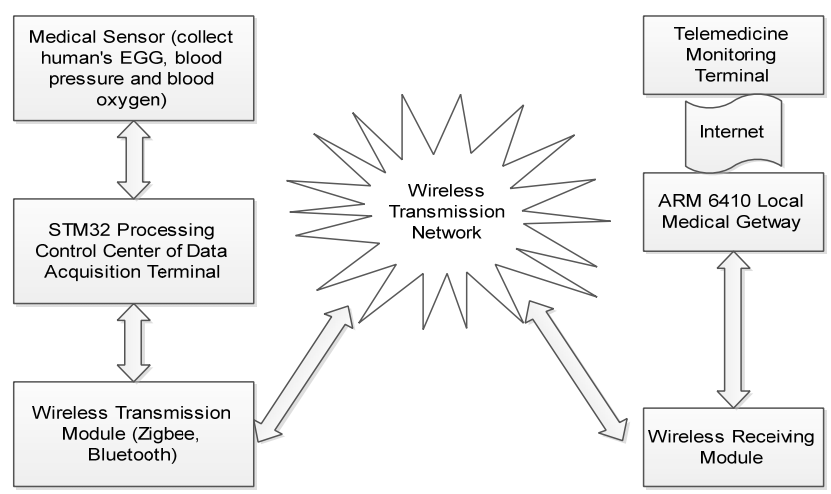

Fig. 1. Diagram of remote intelligent medical data transmission network

The main function of the Monitoring data transmission network system is data remote transmission and collecting human's physiological parameters such as ECG, blood oxygen and blood pressure. The collected data after processed using Bluetooth, Zigbee and network formation to transmit. Processing and displaying the data of physiological parameters is completed by the local medical monitoring gateway ARM6410 (client terminal). The ARM6410 in server terminal is responsible for receiving human physiological data. Network communication between client and server network and data exchange is accomplished by ARM6410 in client terminal and server terminal together.

\section{Overall system design}

Software include human body physiological parameters acquisition module, local medical-treatment gateway module and remote medical monitoring terminal module.

3.1 Program design of physiological medical sensor acquisition module

Program of physiological medical sensor acquisition module mainly needs completing two parts. The first part reads data from ECG, blood oxygen and blood pressure acquisition module, then stores the data in the respective buffer. The second part takes out the data from the respective buffer and sends it through Zigbee or Bluetooth module. The flow diagram of the program as shown in Figure 2.

3.2 Program design of local monitoring network

The program is the kernel of remote intelligent medical monitoring data transmission network which is used for processing data, displaying and remote transmission, and it direct impact to the stability of the software running, the beauty of the interface and the accuracy of the data. In order to realize the independence and concurrency between the parts of the software, the multi-threaded programming mechanism is introduced in the program, including serial data reading thread, interface displaying thread and network transmission thread. In order to ensure the software operated efficiency and save the memory resources of the Android system, these threads will run in the background.

The process of the local monitoring network program design as shown in figure 3. 


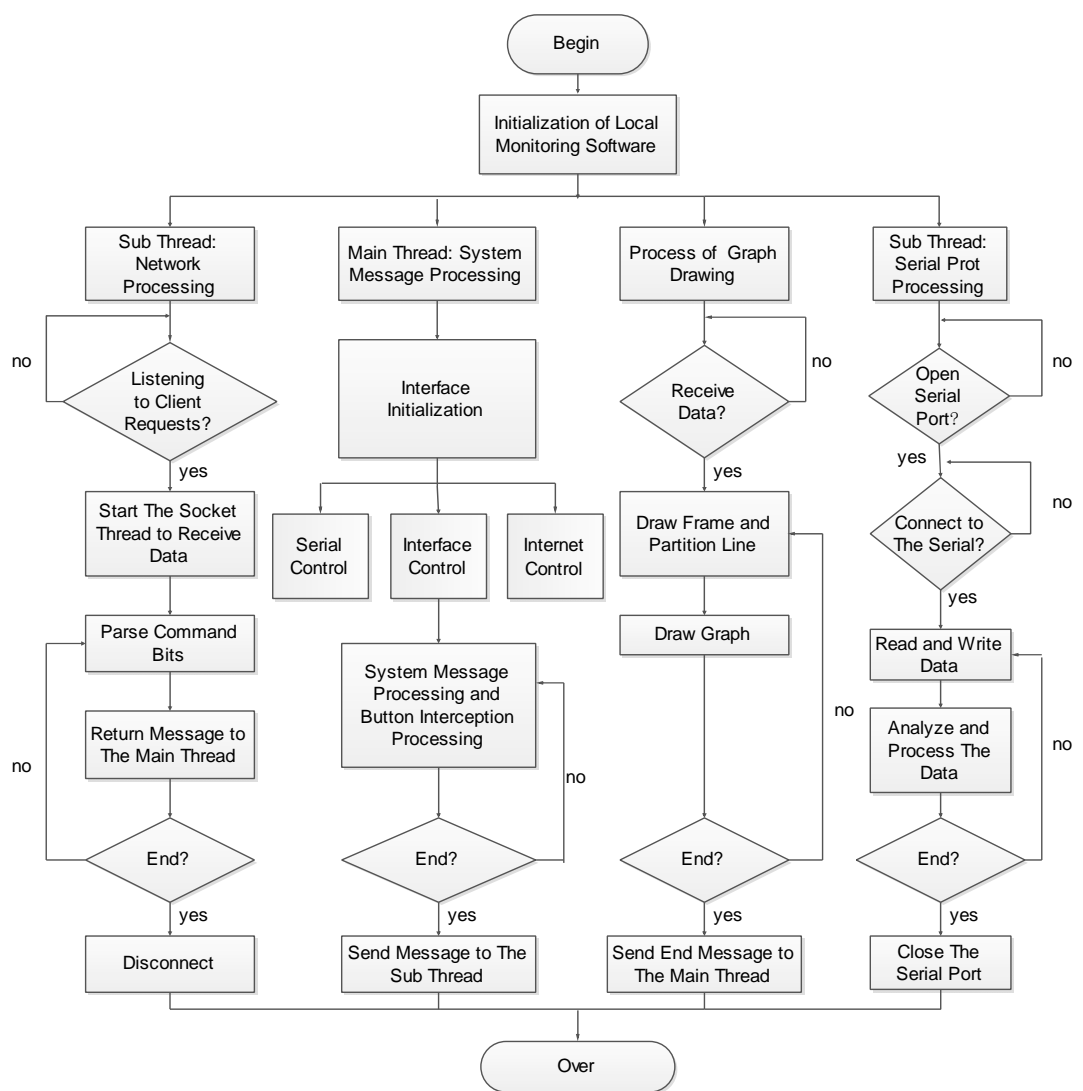

Fig. 2. Flow diagram of local monitoring software

3.3 program design of remote monitoring network

Remote monitoring program design mainly includes two aspects: the page program design and sub-thread program design. Flow diagram of remote monitoring program as shown in figure 4.

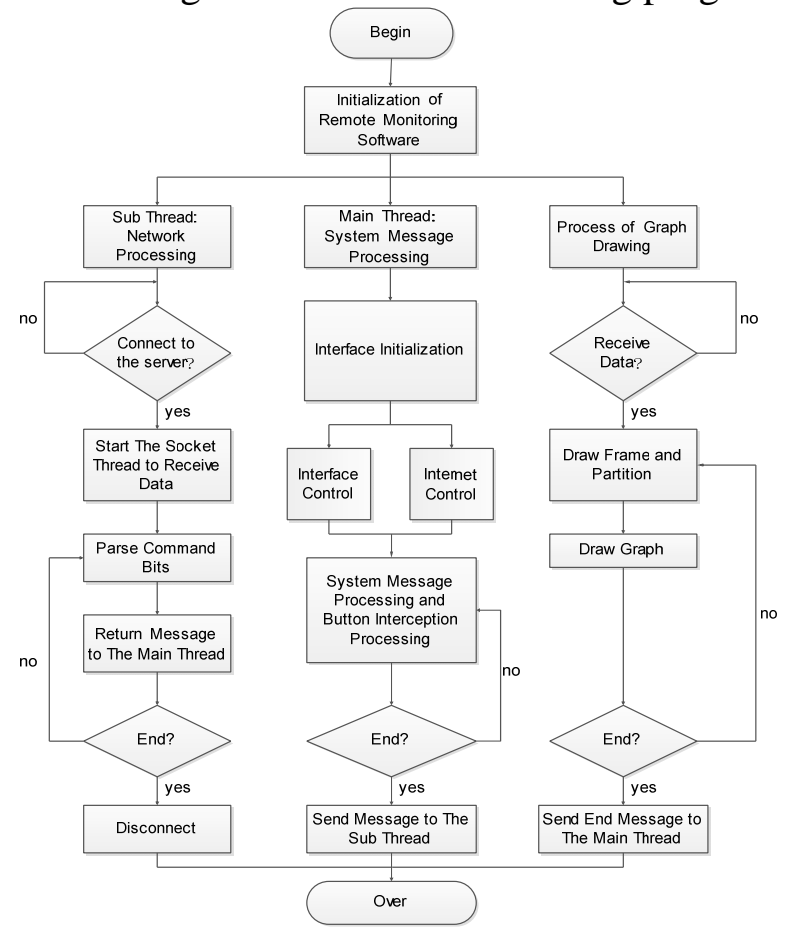

Fig. 3. Flow diagram of remote monitoring software

\section{System testing}

The test is an important part in system development for error checking and error correction which ensure the system is a high-quality and high reliable system. Process of the testing is selecting several typical objects from different populations, testing in different time daily, 
calculating the average value, recording and comparing the data with the result which is collected by high-precision medical equipment, the result as shown in Table 1 . The test results of different measured people is shown in Table 2.

Table 1 . The average result that test in a week from a person

\begin{tabular}{|c|c|c|c|c|c|c|c|c|}
\hline \multirow[t]{2}{*}{ Time } & \multicolumn{2}{|c|}{ Heart Rate (bpm) } & \multicolumn{2}{|c|}{ Pulse Rate (bpm) } & \multicolumn{2}{|c|}{ Oxygen (\%) } & \multicolumn{2}{|c|}{$\begin{array}{c}\text { Systolic pressure/ } \\
\text { Diastolic Pressure } \\
\text { (mmHg) }\end{array}$} \\
\hline & $\begin{array}{l}\text { In This } \\
\text { Paper }\end{array}$ & Medical & $\begin{array}{l}\text { In This } \\
\text { Paper }\end{array}$ & Medical & $\begin{array}{l}\text { In This } \\
\text { Paper }\end{array}$ & Medical & $\begin{array}{l}\text { In This } \\
\text { Paper }\end{array}$ & Medical \\
\hline Monday & 73 & 74 & 61 & 61 & 98 & 99 & $124 / 78$ & $123 / 76$ \\
\hline Tuesday & 75 & 74 & 64 & 65 & 98 & 97 & $121 / 75$ & $124 / 73$ \\
\hline Wednesday & 76 & 77 & 68 & 67 & 99 & 98 & $120 / 70$ & $122 / 71$ \\
\hline Thursday & 75 & 76 & 64 & 62 & 98 & 97 & $123 / 73$ & $125 / 73$ \\
\hline Friday & 74 & 73 & 67 & 66 & 99 & 98 & $122 / 74$ & $123 / 74$ \\
\hline Saturday & 72 & 75 & 66 & 65 & 97 & 97 & $125 / 75$ & $124 / 74$ \\
\hline Sunday & 74 & 75 & 65 & 66 & 98 & 99 & $123 / 72$ & $122 / 72$ \\
\hline
\end{tabular}

Table 2. The result that test from four different people

\begin{tabular}{||c|c|c|c|c|c|c|c|c||}
\hline \multirow{2}{*}{ Number } & \multicolumn{3}{|c|}{ Heart Rate (bpm) } & \multicolumn{2}{|c|}{ Pulse Rate (bpm) } & \multicolumn{2}{c|}{ Oxygen (\%) } & \multicolumn{2}{c|}{$\begin{array}{c}\text { Systolic pressure/ } \\
\text { Diastolic Pressure } \\
\text { (mmHg) }\end{array}$} \\
\hline & $\begin{array}{c}\text { In This } \\
\text { Paper }\end{array}$ & Medical & $\begin{array}{c}\text { In This } \\
\text { Paper }\end{array}$ & Medical & $\begin{array}{c}\text { In This } \\
\text { Paper }\end{array}$ & Medical & $\begin{array}{c}\text { In This } \\
\text { Paper }\end{array}$ & Medical \\
\hline 1 & 75 & 74 & 65 & 66 & 98 & 99 & $123 / 75$ & $124 / 74$ \\
\hline 2 & 76 & 74 & 64 & 64 & 99 & 97 & $122 / 76$ & $124 / 73$ \\
\hline 3 & 74 & 73 & 62 & 64 & 98 & 99 & $124 / 73$ & $122 / 75$ \\
\hline 4 & 74 & 76 & 63 & 61 & 97 & 98 & $120 / 75$ & $123 / 73$ \\
\hline
\end{tabular}

Can see from the table, the measured value from telemedicine monitoring terminal is very close to it from high-precision medical equipment with small error and high accuracy. Telemedicine monitoring terminal can realize the function of remote data transmission. The data measured from different person is relatively stable and the metrical results is helpful to doctors to diagnosing patients' health status.

\section{Reference}

[1] C. Wang, T. Wu, Short rang radio communication and its application to medical monitoring system, Chinese Medical Equipment Journal, 2008,vol. 29, no. 1, pp. 30-34.

[2] J. Luo, Y. Chen, K. Tang, Remote Monitoring Information System and Its Applications Based on the Internet of things //International Conference on Future BioMedical Information Engineering(FBIE), 2009, pp. 482-485.

[3] S. Shen, Q. Fan, P. Zong, Y. Mao, W. Huang, Study on the Architecture and Associated Technologies for Internet of Things, Journal of Nanjing University of Posts and Telecommunications( Natural Science), 2009, vol. 29, no. 6, pp. 1-11.

[4] F. Pinciroli, M. Corso, A. Fuggetta, Telemedicine and E-Health, IEEE Pulse, 2011, vol. 3, no.2, pp. 62-70.

[5] S. Zhang, The Application of Internet of Things in the Intelligent Medical Management, journal of Shandong polytechnic university, 2012, vol. 26, no. 3, pp. 87-89. 